\title{
Interactive Preventive Health Record to Enhance Delivery of Recommended Care: A Randomized Trial
}

Alex H. Krist, $M D, M P H^{1,2}$

Steven H. Woolf, MD, MPH

Stephen F. Rothemich, MD, MS ${ }^{1}$

Robert E. Jobnson, $\mathrm{PbD}^{3}$

J. Eric Peele, $B A^{4}$

Tina D. Cunningham, $P b D^{5}$

Daniel R. Longo, ScD ${ }^{1}$

Ghalib A. Bello, BS ${ }^{3}$

Gary R. Matzke, PharmD ${ }^{6}$

'Department of Family Medicine, Virginia Commonwealth University, Richmond, Virginia

${ }^{2}$ Fairfax Family Practice Residency, Fairfax, Virginia

${ }^{3}$ Departments of Biostatistics and Family Medicine, Virginia Commonwealth University, Richmond, Virginia

${ }^{4}$ RTI International, Research Triangle Park, North Carolina

${ }^{5}$ Graduate Program in Public Health, Eastern Virginia Medical School, Norfolk, Virginia

${ }^{6}$ Department of Pharmacotherapy and Outcomes Science, School of Pharmacy, Virginia Commonwealth University, Richmond, Virginia

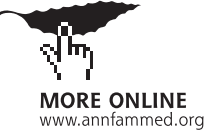

Conflicts of interest: Virginia Commonwealth University bolds the intellectual property rights to the interactive preventive care record evaluated in this study. Although the university and developers are entitled to the system's revenue, MyPreventiveCare is a noncommercial product, and no revenues bave been generated other than grant funding.

\section{CORRESPONDING AUTHOR}

Alex H. Krist, MD, MPH

PO Box 980251

Richmond, VA 23298-0251

ahkrist@vcu.edu

\begin{abstract}
PURPOSE Americans receive only one-half of recommended preventive services. Information technologies have been advocated to engage patients. We tested the effectiveness of an interactive preventive health record (IPHR) that links patients to their clinician's record, explains information in lay language, displays tailored recommendations and educational resources, and generates reminders.
\end{abstract}

METHODS This randomized controlled trial involved 8 primary care practices. Four thousand five hundred patients were randomly selected to receive a mailed invitation to use the IPHR or usual care. Outcomes were measured using patient surveys and electronic medical record data and included IPHR use and service delivery. Comparisons were made between invited and usual-care patients and between users and nonusers among those invited to use the IPHR.

RESULTS At 4 and 16 months, 229 (10.2\%) and 378 (16.8\%) of invited patients used the IPHR. The proportion of patients up-to-date with all services increased between baseline and 16 months by 3.8\% among intervention patients (from $11.4 \%$ to $15.2 \%, P<.001$ ) and by $1.5 \%$ among control patients (from $11.1 \%$ to $12.6 \%, P=.07)$, a difference of $2.3 \%(P=.05)$. Greater increases were observed among patients who used the IPHR. At 16 months, $25.1 \%$ of users were up-todate with all services, double the rate among nonusers. At 4 months, delivery of colorectal, breast, and cervical cancer screening increased by 19\%, 15\%, and $13 \%$, respectively, among users.

CONCLUSIONS Information systems that feature patient-centered functionality, such as the IPHR, have potential to increase preventive service delivery. Engaging more patients to use systems could have important public health benefits.

Ann Fam Med 2012;10:312-319. doi:10.1370/afm.1383.

\section{INTRODUCTION}

mericans receive only one-half of recommended preventive ser-
vices.' Among the various causes is poor access to reliable infor-
mation. Patients need evidence-based information about what is recommended-tailored to their individual risk factors (eg, age, sex, combordities, prior testing, family history, health behaviors) - and presented in an understandable format. ${ }^{2}$ They need reminders when services are due, guidance to deal with inconsistent recommendations, and access to decision aids for choices that require shared decision making. ${ }^{3.5}$ To act on their choices, patients need written plans and logistical details. ${ }^{6,7}$ Clinicians often lack time and resources to provide this information. ${ }^{8}$

One proposed solution is to harness the power of information technology, especially personal health records. For the purposes of this article, personal health records are broadly defined as health information systems used by patients, whereas electronic health records (EHRs) are systems primarily used by clinicians. The existing generation of personal health records can 
give patients direct access to the EHR of their clinician, ${ }^{9,10}$ which is empowering, speeds access to results, and enables patients to discover inaccuracies in their medical record. The next generation of personal health records could offer higher functionality ${ }^{11}$ — assessing patients' needs by applying the latest evidence-based guidelines and incorporating personal medical data to derive individualized recommendations. Taken further, they could link guidance with personalized evidencebased educational resources and decision aids, community services, logistical details, and reminder systems. Automating this process eases the burden on clinicians and moves much of the prevention process outside the confines of the clinical encounter.

There is, however, a shortage of objective evidence that personal health records can achieve these aims, improve outcomes, or even be used. Fewer than 3\% of Americans have an electronic personal health record, ${ }^{12}$ and most of these records lack the above-described functionality. Few are integrated into EHRs. The personal health records that are integrated often fail to explain content in lay language. Some offer preventive services recommendations but rely on simple age- and sex-based logic, ignoring other important risk factors.

We developed and tested a higher-functioning personal health record, called an interactive preventive health record (IPHR). The tool is an online, evidencebased, noncommercial patient portal with the capacity to interface with multiple EHRs and perform the above functions.

\section{METHODS}

We report a patient-level, randomized, nonblinded, controlled comparison of preventive services delivery for patients who were invited to use the IPHR compared with those who received usual care. The study was approved by the Virginia Commonwealth University Institutional Review Board.

\section{Setting}

The Virginia Ambulatory Care Outcomes Research Network recruited 8 primary care practices in Northern Virginia to participate. Practices were members of a private medical group that shared a common EHR (Allscripts Enterprise), managed by a central informatics staff. ${ }^{13}$ Each practice operated independently for clinical activities. Size ranged from 2 to 35 clinicians (median $=7.5$ ). Two sites had 2 clinicians, 5 had 4 to 12 clinicians, and 1 had 35 part-time clinicians and residents.

\section{Participants}

Of the approximately 82,000 active patients (defined as having an office visit for any reason between Novem- ber 2007 and November 2008), 4,500 were randomly selected for participation. Patients selected for participation were stratified equally by practice, sex, and 1 of 4 age categories (18 to 34 years, 35 to 49 years, 50 to 64 years, and 65 to 75 years). Age and sex stratification resulted in a cohort requiring a range of preventive services. The study sample was then randomly assigned by strata to intervention and control groups of 2,250 patients each.

\section{Intervention}

Patients randomized to the intervention group received up to 3 mailed invitations (November 2008, December 2008, and August 2009). The invitations described the importance of prevention and the purpose and value of the IPHR, and each had an identification number that patients could use to create an account.

The IPHR addressed 18 services recommended by the US Preventive Services Task Force (USPSTF). ${ }^{14}$ The IPHR design model was previously published ${ }^{11}$; details about the system are available at http://www.MyPreventiveCare.org. Additionally, sample screen shots are provided online in the Supplemental Appendix, available at http://annfammed.org/content/10/4/312/suppl/ DC1. In brief, patients who visited the IPHR created a password-secure account that linked the system to their EHR. The IPHR extracted 167 clinical data elements to individualize preventive services recommendations. Patients also completed a health risk assessment, including race-ethnicity, family history, health behaviors, and some past test results not contained in the EHR.

Based on this information and the USPSTF guidelines, the IPHR applied programmed logic to generate a personally tailored list of prevention recommendations. The interface offered patients hyperlinks to detailed personal messages that explained the preventive service and its rationale, referenced relevant details in the patient's history (eg, prior laboratory test values and dates), included links to evidence-based educational material and decision aids, and summarized the next steps. Message content was modeled after http:// www. Healthfinder.gov. ${ }^{15}$ After a patient used the IPHR, the system automatically forwarded a summary to the EHR in-box of the patient's clinician.

Control patients received usual preventive care. They received no mailings about the IPHR and were unable to access the system.

\section{Outcome Measures}

Measured outcomes included IPHR utilization and 2 primary preventive service delivery measures. Utilization was defined as the percentage of patients who were mailed an invitation to visit the IPHR, established an account, and received prevention recommendations. 
Service delivery measures included (1) percentage of eligible patients up-to-date with all indicated services (all-or-none measure), and (2) average percentage of up-to-date indicated services for all patients (composite measure). The percentages of eligible patients who were up-to-date with each individual service were treated as secondary measures. Eligibility for the service and upto-date status was based on April 2009 USPSTF recommendations. Prostate cancer screening was excluded from the composite and all-or-none measures.

\section{Data Collection}

Outcomes data were collected from the EHR database and patient postal survey responses. EHR data elements included age, sex, diagnoses, medications, vital signs, smoking history, immunizations, and values and dates of laboratory test results. EHR data were obtained for all intervention and control patients. All personal identifiers other than the medical record number were removed, allowing for a waiver of written consent. The outcomes survey questions asked patients when services were last delivered and about family history, health behaviors, height, weight, race-ethnicity, education, and Internet use. Survey questions were modeled after those used by the Behavioral Risk Factor Surveillance System and National Health Interview Survey. ${ }^{16,17}$ As determined by a modified Dillman technique, ${ }_{1}^{18,19}$ patients were mailed an outcomes survey questionnaire in the spring of 2007 (baseline) and in the spring of 2008 and 2009 (4 and 16 months after the first IPHR invitation, respectively).

\section{Statistical Analysis}

EHR data and survey questionnaire responses were merged, and discrepant information was reconciled by using the source with the most current date. Information about health behaviors obtained from patient survey questionnaires superseded EHR data. Services with missing values from both sources were considered not up-to-date.

The intention-to-treat analysis compared the allor-none and composite measures for the intervention and control groups. A subgroup analysis that focused exclusively on intervention patients compared outcomes among patients who used (users) and did not use (nonusers) the IPHR. We calculated the increase in service delivery from baseline to 4 months and from baseline to 16 months for each measure in each group. For both the intention-to-treat and subgroup analyses, we calculated differences between groups in the magnitude of change in service delivery over time:

[Intervention patients up-to-date with service (at 4 or 16 months)-(baseline)]-[Control patients up-to-date with service (at 4 or 16 months)-(baseline)].
This difference in the magnitude of change was selected as the primary outcome to account for confounding and temporal factors. The study was powered to detect differences only in the all-or-none and composite measures, not in the delivery of individual services.

To adjust for self-selection and potential clustering of factors that might independently influence preventive service use, analyses were adjusted for patient age and sex, practice location, and whether the patient responded to both the pre- and post-intervention survey. The latter was not used to adjust health behavior data, because these values were measured only by survey. The individual service measures were modeled using SAS/GLIMMIX to perform generalized logistic regression allowing for correlated observations at two time periods. The all-or-none and composite measures were modeled using SAS/MIXED, which also accounts for correlated measures. Assuming a 50\% survey response rate and an $85 \%$ item response for the fraction of sampled patients eligible for specific preventive services, a sample size of 4,500 patients provided $80 \%$ power to detect a $5 \%$ difference in the primary outcomes. Statistical calculations were performed in SAS 9.2 (SAS Institute, Inc).

\section{RESULTS}

\section{Study Population}

Control and intervention patients had similar demographic characteristics (Table 1). During the 66 weeks, $378(16.8 \%)$ of 2,250 intervention patients established an account and received prevention recommendations (users) (Figure 1). Although more patients registered for the IPHR in the first 4 weeks after each mailing, patients continued to register up to 30 weeks after each mailing despite the absence of further prompts.

Nonusers were demographically similar to the control group. Users were older than nonusers (mean age 55.9 years vs 49.5 years, $P<.001$ ) and more likely to be male $(55.8 \%$ vs $48.9 \%, P=.02)$, non-Hispanic $(97.3 \%$ vs $93.1 \%, P=.02)$, and college educated $(69.9 \%$ vs $62.8 \%, P=.03$ ). Users also had more comorbidities (eg, $38.6 \%$ vs $26.1 \%, P<.001$, with hypertension) and were more likely to be daily Internet users $(80.7 \%$ vs $71.4 \%$, $P=.002)$ than nonusers.

The baseline patient survey response rate was $50.8 \%$; the response rates for the 4 -month and 16 -month surveys were $46.5 \%$ and $48.9 \%$, respectively. Control and intervention patients were equally likely to complete at least 1 survey questionnaire $(69.9 \%$ vs $67.6 \%, P=.1)$, whereas users were more likely than nonusers to complete at least 1 survey questionnaire $(89.7 \%$ vs $63.1 \%, P<.001)$. 
Table 1. Characteristics of Intervention and Control Patients

\begin{tabular}{|c|c|c|c|c|}
\hline \multirow[b]{2}{*}{ Characteristic } & \multirow{2}{*}{$\begin{array}{c}\text { Control } \\
\text { Population } \\
(n=2,250) \\
\text { No. }(\%)\end{array}$} & \multirow{2}{*}{$\begin{array}{c}\text { Intervention } \\
\text { Population } \\
\text { (n=2,250) } \\
\text { No. }(\%)\end{array}$} & \multicolumn{2}{|c|}{$\begin{array}{c}\text { Intervention Population } \\
\text { Subgroup Analysis }\end{array}$} \\
\hline & & & $\begin{array}{c}\text { Nonusers } \\
(\mathrm{n}=1,872) \\
\text { No. }(\%)\end{array}$ & $\begin{array}{l}\text { Users }^{\mathrm{a}} \\
(\mathrm{n}=378) \\
\text { No. }(\%)\end{array}$ \\
\hline \multicolumn{5}{|l|}{ Age, years } \\
\hline $18-34$ & $446(19.8)$ & $444(19.7)$ & $413(22.0)$ & $31(8.2)$ \\
\hline $35-49$ & $675(30.0)$ & $677(30.1)$ & $580(31.0)$ & $97(25.7)$ \\
\hline $50-64$ & $676(30.0)$ & $676(30.0)$ & $524(28.0)$ & $152(40.2)$ \\
\hline $65-75$ & $453(20.1)$ & $453(20.1)$ & $355(19.0)$ & $98(25.9)$ \\
\hline \multicolumn{5}{|l|}{ Sex } \\
\hline Male & $1125(50.0$ & $1,126(50.0)$ & $915(48.9)$ & $211(55.8)$ \\
\hline Female & 1125 (50.0) & $1,124(50.0)$ & $957(51.1)$ & $167(44.2)$ \\
\hline \multicolumn{5}{|l|}{ Race $^{b}$} \\
\hline White & 1,251 (79.6) & 1,206 (79.2) & $923(78.1)$ & $283(83.5)$ \\
\hline African American & $93(6.0)$ & $100(6.6)$ & $78(6.6)$ & $22(6.5)$ \\
\hline Asian & $149(9.4)$ & $145(9.5)$ & $120(10.1)$ & $25(7.4)$ \\
\hline Other & $63(4.0)$ & $51(3.4)$ & $42(3.6)$ & $9(2.6)$ \\
\hline Unknown & $16(1.0)$ & $19(1.3)$ & 19 (1.6) & $0(0.0)$ \\
\hline \multicolumn{5}{|l|}{ Hispanic ethnicity ${ }^{b}$} \\
\hline Hispanic & $95(6.0)$ & $90(5.9)$ & $81(6.9)$ & $9(2.7)$ \\
\hline Non-Hispanic & $1,477(94.0)$ & $1,431(94.1)$ & 1,101 (93.1) & $330(97.3)$ \\
\hline \multicolumn{5}{|l|}{ Education $^{b}$} \\
\hline College or higher & $777(67.7)$ & $735(64.5)$ & $540(62.8)$ & $195(69.9)$ \\
\hline Less than college & $371(32.3)$ & 404 (35.5) & $320(37.2)$ & $84(30.1)$ \\
\hline \multicolumn{5}{|l|}{ Comorbidities } \\
\hline Diabetes & $208(9.2)$ & $192(8.5)$ & $153(8.2)$ & $39(10.3)$ \\
\hline Cancer & $68(3.0)$ & $75(3.3)$ & $55(2.9)$ & $20(5.3)$ \\
\hline $\begin{array}{l}\text { Coronary artery } \\
\text { disease }\end{array}$ & $96(4.3)$ & $98(4.4)$ & $75(4.0)$ & $23(6.1)$ \\
\hline Hyperlipidemia & $733(32.6)$ & $696(30.9)$ & $544(29.1)$ & $152(40.2)$ \\
\hline Hypertension & $646(28.7)$ & $634(28.2)$ & $488(26.1)$ & $146(38.6)$ \\
\hline $\begin{array}{l}\text { Use Internet at least } \\
\text { once per dayb }\end{array}$ & 868 (75.6) & $839(73.7)$ & $614(71.4)$ & $225(80.7)$ \\
\hline \multicolumn{5}{|c|}{$\begin{array}{l}\text { a There were statistically significant differences between users and nonusers for age }(P<.001) \text {, sex } \\
(P=.02) \text {, ethnicity }(P=.04) \text {, education }(P=.03) \text {, percentage with cancer }(P=.03) \text {, percentage with hyper- } \\
\text { lipidemia }(P<.001) \text {, percentage with hypertension }(P<.001) \text {, and Internet use }(P=.002) \text {. } \\
\text { b Only includes survey respondents, as data were not available in the electronic health record. }\end{array}$} \\
\hline
\end{tabular}

$25.1 \%, P<.001)$ at 16 months, compared with a $2.2 \%$ increase (from $11.7 \%$ to $13.9 \%, P=.03$ ) among nonusers - a difference in increase of up-to-date users vs nonusers of 9.3\% $(P=.002)$ (Table 3$)$.

\section{Composite Measure}

Over 4 months (Table 2), the proportion of indicated preventive services received by intervention patients (composite measure) increased by $1.4 \%$ (from $61.7 \%$ to $63.1 \%, P=.03$ ) but changed little among controls. Over 16 months, the proportion of up-to-date preventive services decreased by $2.2 \%$ (from $61.4 \%$ to $59.2 \%, P<.001)$ for control patients, but did not change for intervention patients. The net change did not differ significantly between intervention and control patients in the intention-to-treat analysis for either period (Table 3 ). The net change strongly differed in the subgroup analysis, however. Among users, the percentage of indicated preventive services increased by $5.2 \%$ (from $64.9 \%$ to $70.1 \%, P<.001)$ and $3.5 \%$ (from $64.9 \%$ to $69.4 \%, P<.001$ ) at 4 months and 16 months, respectively (Table 2). Among nonusers, the percentage of indicated services that were up-to-date did not change at 4 months and decreased $2.4 \%$ at 16 months (from $60.9 \%$ to $58.5 \%$, $P=.002)$. The net increase in the composite measure among users and

\section{Overall Delivery of Preventive Services}

\section{All-or-None Measure}

In the intention-to-treat analysis, the percentage of intervention patients who were up-to-date with all indicated preventive services increased by $2.1 \%$ (from $11.4 \%$ to $13.5 \%, P=.02$ ) and $3.8 \%$ (from $11.4 \%$ to $15.2 \%, P<.001)$ at 4 and 16 months, respectively. Similar changes were not observed in the control population (baseline to 16-month increase from $11.1 \%$ to $12.6 \%, P=.07$ (Table 2 ). At 16 months, the net increase in the percentage of patients who were upto-date was $2.3 \%$ greater $(P=.05)$ among intervention than control patients. In the subgroup analysis, even greater changes were observed among users. The percentage of users who were up-to-date with all preventive services increased by $11.5 \%$ (from $13.6 \%$ to nonusers was $4.6 \%(P=.004)$ and $6.9 \%(P<.001)$ at 4 and 16 months, respectively.

\section{Delivery of Specific Preventive Services}

Changes were observed in the proportion of patients who were up-to-date with specific preventive services at 4 and 16 months, with salutary changes observed in both the intervention and control groups (Table 2). As expected, based on the power calculation, the magnitude of change between intervention and control patients for any specific preventive service did not differ significantly in the intention-to-treat comparison. The net improvement in the uptake of some services, however, was striking in the subgroup comparison (Table 3). For example, among users, the delivery of some services increased by $9 \%$ to $23 \%$. The difference 
between users and nonusers in the increase in up-todate services at 4 months was $15.3 \%(P=.007), 12.3 \%$ $(P=.03)$, and $11.3 \%(P=.01)$ for colorectal, breast, and cervical cancer screening, respectively. Similar changes were seen at 16 months, except for breast cancer screening.

Increases in preventive service delivery, including the overall and specific service measures, were similar for patients who used the IPHR after the first (early adopters), second, or third (late adopters) invitational mailing.

\section{DISCUSSION}

Patients who were mailed an invitation to use the IPHR were more likely to be up-to-date on all indicated preventive services than were patients who received usual care. When IPHR users were compared with nonusers, the benefits appeared to be substantially greater. In fact, at 16 months, 1 in 4 users were up-to-date on all preventive services - nearly double that of nonusers. Attention to confounding variables is important, but a causal effect from the IPHR is further suggested by large increases in the delivery of specific preventive services for users, such as cancer screening and immunizations, compared with little or no increase in the control and nonuser groups.

The compelling health benefits established by the USPSTF for these preventive services suggests that the increased delivery rates observed in this study would have important implications for reducing morbidity

\section{Figure 1. New interactive preventive health record (IPHR) users based on invitations mailed to patients.}

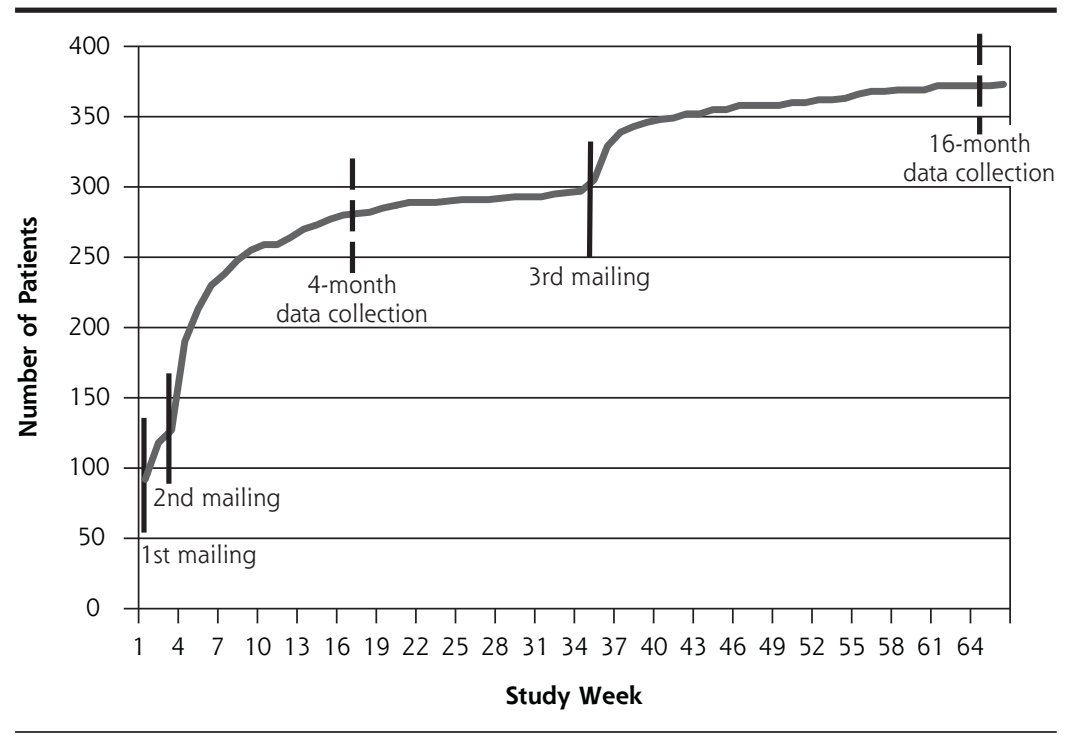

Note: Number of patients who logged onto the IPHR, established an account, and received prevention recommendations. A total of 2,250 invitations were mailed (intervention population). and mortality. The specific services that exhibited the largest increase were those identified by the National Commission on Prevention Priorities as saving the most quality-adjusted life years if delivery were optimized. ${ }^{20}$ The increased uptake of preventive services observed among users is consistent with the benefits observed for other interventions to promote delivery, such as reminders, self-management support, tailored education, clinician-community linkages, and practice redesign. ${ }^{21-29}$ Interestingly, the services most likely to improve were screening tests and immunizations. Changes were not observed for health behavior counseling, even among users. Studies suggest that intensive support is needed to help patients modify lifestyle, something that technology alone is not currently able to accomplish. ${ }^{30,31}$ We have previously reported that using technology to refer patients to community-based resources for intensive counseling is associated with a reduction in body mass index and smoking rates. ${ }^{32}$

Although the findings of this study are encouraging, only 1 intention-to-treat analysis achieved statistical significance, and the magnitude of change was small. One factor was the small absolute number of IPHR users, which provided inadequate power to show changes in effectiveness outcomes for the entire intervention population. When conducting the power analysis for the study, we assumed, based on pilot work completed in 2004, that $50 \%$ of patients mailed an invitation would create an account. In that project offices directed patients to an IPHR prototype when calling to schedule a wellness visit- $78 \%$ of invited patients used the prototype. In the current study, however, promotion of the IPHR was more subtle. Invitations were mailed to random patients not associated with an upcoming visit. Practices did not promote the IPHR at visits and did not integrate the tool into routine activities. Subsequent focus groups with nonusers found that many did not think the IPHR was intended for them, because they had recently been to the office and heard nothing about it, or they planned to use the IPHR before a visit at a future date.

Recent evidence, in which aggressive promotion of personal health records by 2 large health systems resulted in annual adoption by only $10 \%$ to $20 \%$ of patients, suggests that our adop- 
tion rate $(16.8 \%)$ is favorable for promotion based on a simple mailed invitation. ${ }^{33,34}$ Motivating even more patients to use a personal health record with advanced functionality may require practices to make major changes. To understand the value and relevance to care, patients may need information about the tool, how it works, and why it is important for them. This information is perhaps best explained during the course of multiple patient contacts and reinforced by all health care team members. Practices may need a wide range of resources and tools to inform patients of the new system, such as informational brochures, vid-

Table 2. Percentage of Up-to-Date Preventive Services at Baseline, 4 Months, and 16 Months Postintervention

\begin{tabular}{|c|c|c|c|c|c|c|c|c|c|c|c|c|}
\hline \multirow[b]{3}{*}{$\begin{array}{l}\text { Indicated } \\
\text { Preventive Services }\end{array}$} & \multirow{2}{*}{\multicolumn{3}{|c|}{$\begin{array}{l}\text { Control Population } \\
\quad(n=2,250)\end{array}$}} & \multirow{2}{*}{\multicolumn{3}{|c|}{$\begin{array}{l}\text { Intervention } \\
\text { Population } \\
(n=2,250)\end{array}$}} & \multicolumn{6}{|c|}{ Intervention Population Subgroup Analysis } \\
\hline & & & & & & & \multicolumn{3}{|c|}{ Nonusers $(n=1,872)$} & \multicolumn{3}{|c|}{ Users $(n=378)$} \\
\hline & $\infty^{0}$ & $\sigma^{\circ}$ & 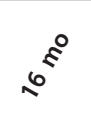 & $0^{0}$ & $\alpha^{\circ}$ & $0^{\circ}$ & $\infty^{0}$ & $\Omega^{\circ}$ & $0^{\circ}$ & $\infty^{0^{2}}$ & $\sigma^{\circ}$ & $0^{\circ}$ \\
\hline \multicolumn{13}{|c|}{ Overall delivery of indicated preventive services } \\
\hline $\begin{array}{l}\text { Patients up-to-date } \\
\text { on all indicated } \\
\text { services (all-or-none } \\
\text { measure) }\end{array}$ & 11.1 & 12.1 & 12.6 & 11.4 & $13.5^{\mathrm{a}, \mathrm{b}}$ & $15.2^{\mathrm{b}, \mathrm{c}}$ & 11.7 & 13.4 & $13.9^{b, d}$ & 13.6 & 17.8 & $25.1^{b, c}$ \\
\hline $\begin{array}{l}\text { Percentage of up-to- } \\
\text { date services (com- } \\
\text { posite measure) }\end{array}$ & 61.4 & 62.1 & $59.2^{c, e}$ & 61.7 & $63.1^{b, d}$ & 60.4 & 60.9 & 61.5 & $58.5^{a, e}$ & 64.9 & $70.1^{\mathrm{b}, \mathrm{c}}$ & $69.4^{\mathrm{a}, \mathrm{b}}$ \\
\hline \multicolumn{13}{|c|}{ Delivery of specific preventive services } \\
\hline $\begin{array}{l}\text { Colorectal cancer } \\
\text { screening }\end{array}$ & 36.8 & 40.4 & $43.9^{b, d}$ & 37.7 & $45.2^{\mathrm{a}, \mathrm{b}}$ & $47.8^{b, c}$ & 40.0 & 43.9 & $46.6^{a, b}$ & 53.0 & $72.2^{\mathrm{a}, \mathrm{b}}$ & $73.9^{\mathrm{b}, \mathrm{c}}$ \\
\hline $\begin{array}{l}\text { Breast cancer } \\
\text { screening }\end{array}$ & 44.1 & $53.2^{\mathrm{b}, \mathrm{d}}$ & $29.6^{c, e}$ & 52.4 & 58.5 & $35.8^{c, e}$ & 52.9 & 55.7 & $36.2^{c, e}$ & 75.1 & $90.1^{\mathrm{b}, \mathrm{d}}$ & 66.1 \\
\hline $\begin{array}{l}\text { Cervical cancer } \\
\text { screening }\end{array}$ & 67.6 & 71.8 & 68.4 & 72.7 & 74.9 & 73.3 & 71.5 & 72.0 & 71.0 & 79.5 & $91.2^{a, b}$ & $92.4^{\mathrm{a}, \mathrm{b}}$ \\
\hline $\begin{array}{l}\text { Prostate cancer } \\
\text { screening }\end{array}$ & 56.8 & $46.5^{c, e}$ & $48.9^{a, e}$ & 50.8 & 48.5 & 52.3 & 47.0 & 46.2 & 52.0 & 71.8 & 65.0 & 62.0 \\
\hline $\begin{array}{l}\text { Hypertension } \\
\text { screening }\end{array}$ & 99.9 & $98.1^{\text {cee }}$ & 93.0 ce & 100.0 & $98.6^{c, e}$ & $92.8^{c, e}$ & 99.9 & $94.5^{c, e}$ & $79.9^{c, e}$ & 100.0 & 99.5 & $96.6^{\text {c,e }}$ \\
\hline $\begin{array}{l}\text { Hypercholesterolemia } \\
\text { screening }\end{array}$ & 82.8 & $86.0^{a, b}$ & $85.9^{b, d}$ & 80.7 & $83.2^{b, d}$ & $85.2^{b, c}$ & 79.7 & 82.1 & $84.5^{b, c}$ & 91.1 & 93.2 & 93.3 \\
\hline $\begin{array}{l}\text { Abdominal aortic } \\
\text { aneurysm screening }\end{array}$ & 24.0 & 22.7 & 25.3 & 24.6 & 23.7 & 25.4 & 28.5 & 22.7 & 22.6 & 15.4 & 25.9 & 32.1 \\
\hline Diabetes screening & 77.1 & 80.6 & $82.0^{a, b}$ & 74.9 & $81.3^{a, b}$ & $84.5^{b, c}$ & 76.1 & $82.6^{a, b}$ & $84.9^{b, c}$ & 87.9 & 90.6 & $96.7^{\mathrm{a}, \mathrm{b}}$ \\
\hline Chlamydia screening & 21.1 & 10.2 & 21.7 & 17.8 & 10.0 & 21.3 & - & - & - & - & - & - \\
\hline $\begin{array}{l}\text { Osteoporosis } \\
\text { screening }\end{array}$ & 39.7 & 41.9 & 48.5 & 45.2 & 51.1 & $57.9^{b, d}$ & 38.2 & 41.0 & $51.7^{\mathrm{b}, \mathrm{d}}$ & 72.0 & 90.6 & 96.3 \\
\hline $\begin{array}{l}\text { Aspirin chemopro- } \\
\text { phylaxis use }\end{array}$ & 53.1 & 58.9 & 58.8 & 61.0 & 56.8 & 57.6 & 61.8 & 56.7 & 55.5 & 58.3 & 57.1 & 64.8 \\
\hline Tetanus immunization & 46.9 & $52.3^{a, b}$ & $51.4^{a, b}$ & 46.4 & $52.8^{\mathrm{b}, \mathrm{c}}$ & $52.8^{b, c}$ & 51.1 & $55.7^{a, b}$ & $55.7^{a, b}$ & 57.6 & $70.9^{a, b}$ & $72.6^{\mathrm{b}, \mathrm{c}}$ \\
\hline $\begin{array}{l}\text { Influenza } \\
\text { immunization }\end{array}$ & 30.7 & 28.6 & 27.5 & 29.6 & 30.3 & 30.6 & 29.2 & 28.8 & 29.6 & 37.3 & 42.1 & 40.7 \\
\hline $\begin{array}{l}\text { Pneumococcal } \\
\text { immunization }\end{array}$ & 22.5 & $27.8^{\mathrm{a}, \mathrm{b}}$ & $30.9^{b, c}$ & 20.8 & $28.9^{b, c}$ & $34.9^{b, c}$ & 25.2 & $33.2^{a, b}$ & $39.3^{b, c}$ & 48.2 & $62.4^{a, b}$ & $71.1^{b, c}$ \\
\hline $\begin{array}{l}\text { Smoking cessation } \\
\text { counseling }\end{array}$ & 80.1 & 80.2 & 71.5 & 70.1 & 75.0 & 73.7 & 69.7 & 79.5 & 78.2 & 70.4 & 62.4 & 54.0 \\
\hline Dietary counseling & 15.0 & 17.3 & 14.7 & 16.1 & 17.8 & 17.5 & 15.7 & 18.4 & 17.6 & 16.5 & 15.7 & 17.0 \\
\hline Exercise counseling & 18.8 & 16.2 & 18.2 & 18.8 & 20.2 & 18.5 & 18.1 & 19.3 & 18.0 & 19.5 & 21.5 & 18.4 \\
\hline $\begin{array}{l}\text { Weight loss } \\
\text { counseling }\end{array}$ & 51.8 & 53.1 & 47.9 & 51.1 & 48.5 & 46.1 & 56.1 & 54.0 & 49.6 & 47.0 & 40.7 & 47.0 \\
\hline \multicolumn{13}{|c|}{$\begin{array}{l}\text { Notes: All values adjusted for age, sex, practice location, and survey response, except abdominal aortic aneurysm screening, Chlamydia screening, and aspirin chemo- } \\
\text { prophylaxis use, for which sample sizes were too small for adjusting (ie, these values are unadjusted). P values compare the 4-month or the } 16 \text {-month up-to-date value } \\
\text { with the baseline up-to-date value. }\end{array}$} \\
\hline $\begin{array}{l}\text { a } P<.02 \text {. } \\
\text { b Statistically significant incre } \\
\text { c } P<.001 \text {. } \\
\text { d } P<.05 \text {. } \\
\text { e Statistically significant decr }\end{array}$ & ase in se & e delivery & & & & & & & & & & \\
\hline
\end{tabular}




\begin{tabular}{|c|c|c|c|c|}
\hline \multirow[b]{2}{*}{ Indicated Preventive Services } & \multicolumn{2}{|c|}{$\begin{array}{l}\text { Intervention } \\
\text { vs Control } \\
\text { (Intention } \\
\text { to Treat) }\end{array}$} & \multicolumn{2}{|c|}{$\begin{array}{l}\text { Users vs } \\
\text { Nonusers } \\
\text { (Subgroup } \\
\text { Analysis) }\end{array}$} \\
\hline & $4 \mathrm{mo}$ & $16 \mathrm{mo}$ & $4 \mathrm{mo}$ & $16 \mathrm{mo}$ \\
\hline \multicolumn{5}{|c|}{ Overall delivery of indicated preventive services } \\
\hline $\begin{array}{l}\text { Patients up-to-date on all indicated } \\
\text { services (all-or-none measure) }\end{array}$ & 1.1 & $2.3^{\mathrm{a}, \mathrm{b}}$ & 2.4 & $9.3^{b, c}$ \\
\hline $\begin{array}{l}\text { Percentage of up-to-date services } \\
\text { (composite measure) }\end{array}$ & 0.7 & 1.0 & $4.6^{\mathrm{b}, \mathrm{c}}$ & $6.9^{b, d}$ \\
\hline \multicolumn{5}{|c|}{ Delivery of selected, specific preventive services } \\
\hline Colorectal cancer screening & 3.9 & 2.9 & $15.3^{b, c}$ & $14.2^{b, c}$ \\
\hline Breast cancer screening & -2.9 & -1.9 & $12.3^{\mathrm{a}, \mathrm{b}}$ & 7.7 \\
\hline Cervical cancer screening & -2.1 & -0.3 & $11.3^{b, c}$ & $13.4^{b, c}$ \\
\hline Tetanus immunization & 1.0 & 2.0 & $8.7^{\mathrm{b}, \mathrm{c}}$ & $10.3^{b, c}$ \\
\hline Influenza immunization & 2.9 & 4.3 & 5.2 & 3.0 \\
\hline Pneumococcal immunization & 2.8 & 5.7 & 6.3 & 8.9 \\
\hline \multicolumn{5}{|l|}{ a $P<.05}$. \\
\hline \multicolumn{5}{|c|}{$\begin{array}{l}\text { b Statistically significant increase in net service delivery for intervention patients or users. } \\
\text { C } P<.02 \text {. } \\
\text { d } P<.001 .\end{array}$} \\
\hline
\end{tabular}

eos, and links on their practice website. These practice integrations may not be possible unless practices modify daily activities and workflow to include their personal health record. Our contention that a robust practice implementation is necessary for the adoption of the IPHR is a hypothesis we are actively exploring in our current studies.

This study has several important limitations. First, the Northern Virginia patients seen by the study sites were well educated, had high incomes, and were predominantly non-Hispanic whites. Whether findings in this setting would generalize to other populations is unknown. Second, the subgroup analysis, comparing users and nonusers, can be influenced by selection bias. Users were demographically different than nonusers (eg, fewer minorities and higher education), had more chronic illnesses, and were more up-to-date with care at baseline. They may have been more interested in receiving preventive services and may have had better access to care (eg, better health insurance) than nonusers. Finally, users were more likely to complete the survey questionnaires than nonusers. Although these limitations are important, only data for diet, exercise, and weight loss counseling derived solely from survey responses $;$ the delivery of all other services was measured with both EHR and survey data. Randomization would eliminate the selection bias for the intentionto-treat analysis. The disparity in baseline utilization rates was controlled by comparing before and after differences in preventive service delivery for users and nonusers. The high socioeconomic status of the study sites does warrant further research to determine whether similar benefits would be seen in other settings.

Increasingly, patient-centered information systems are recommended as an essential tool to improve the delivery of care and health. ${ }^{28,35-38}$ The functionality of many systems is lacking, however, and there is insufficient evidence to show that they can support their intended use. This study shows that the IPHR and similar systems can improve important patient outcomes, such as the delivery of evidence-based preventive care. To have a broad impact on public health, attention is needed to ensure that future personal health records can deliver higher levels of functionality, similar to the IPHR, and that a greater proportion of patients and clinicians actively use the systems.

To learn how to use your personal health record for prevention, A How-To Guide for Using Patient-Centered Personal Health Records to Promote Prevention, from the Agency for Healthcare Research and Quality, is available at http://healthit.ahrq.gov/KRIST-IPHR-Guide-0612.pdf.

To read or post commentaries in response to this article, see it online at http://www.annfammed.org/content/10/4/312.

Key words: health promotion; information management; informatics; primary health care; patient-centered care

Submitted September 2, 2011; submitted, revised, December 19, 2011; accepted January 6, 2012.

Funding support: This work was supported by the Agency for Healthcare Research and Quality (R18 HS17046-01).

Trial registration: Clinicaltrials.gov identifier: NCT00589173.

Acknowledgments: The authors thank the participating study practices: Fairfax Family Practice, Gainesville Family Medicine, Herndon Family Medicine, Lorton Station Family Medicine, Prince William Family Medicine, South Riding Family Medicine, Town Center Family Medicine, and Vienna Family Medicine. We thank Melissa Hayes and Kristin Schmidt for project assistance; and Steven Mitchell and John Loomis for database and EHR support. We received invaluable advice and assistance designing the IPHR from Linda Harris, PhD; William Kerns, MD; Anton Kuzel, MD, MHPE; Adam Bowen; Thomas Ehrlich, MD; and Terrence McCormally, MD.

\section{References}

1. McGlynn EA, Asch SM, Adams J, et al. The quality of health care delivered to adults in the United States. N Engl J Med. 2003;348 (26):2635-2645. 
2. Goldstein MG, Whitlock EP, DePue J; Planning Committee of the Addressing Multiple Behavioral Risk Factors in Primary Care Project. Multiple behavioral risk factor interventions in primary care. Summary of research evidence. Am J Prev Med. 2004;27(2)(Suppl):61-79.

3. McNutt RA. Shared medical decision making: problems, process, progress. JAMA. 2004;292(20):2516-2518.

4. O'Connor AM, Stacey D, Entwistle V, et al. Decision aids for people facing health treatment or screening decisions. Cochrane Database Syst Rev. 2003;(2):CD001431.

5. O'Connor AM, Légaré F, Stacey D. Risk communication in practice: the contribution of decision aids. BMJ. 2003;327(7417):736-740.

6. Stone EG, Morton SC, Hulscher ME, et al. Interventions that increase use of adult immunization and cancer screening services: a meta-analysis. Ann Intern Med. 2002;136(9):641-651.

7. Ramsay CR, Eccles M, Grimshaw JM, Steen N. Assessing the longterm effect of educational reminder messages on primary care radiology referrals. Clin Radiol. 2003;58(4):319-321.

8. Stange KC, Zyzanski SJ, Jaén CR, et al. Illuminating the 'black box'. A description of 4454 patient visits to 138 family physicians. J Fam Pract. 1998;46(5):377-389.

9. Tang PC, Ash JS, Bates DW, Overhage JM, Sands DZ. Personal health records: definitions, benefits, and strategies for overcoming barriers to adoption. J Am Med Inform Assoc. 2006;13(2):121-126.

10. Tang PC, Lee TH. Your doctor's office or the Internet? Two paths to personal health records. N Engl J Med. 2009;360(13):1276-1278.

11. Krist AH, Woolf $\mathrm{SH}$. A vision for patient-centered health information systems. JAMA. 2011;305(3):300-301.

12. Markle Foundation. Connecting for Health. Americans overwhelmingly believe electronic personal health records could improve their health. http://www.connectingforhealth.com/resources/ResearchBrief-200806.pdf. Accessed May 2009.

13. Fairfax Family Practice Centers. Welcome to Fairfax Family Practice Centers. http://fairfaxfamilypracticecenters.com/. Accessed Jul 2010.

14. U.S. Preventive Services Task Force. Preventive Services. http:// www.ahrq.gov/clinic/uspstfix.htm. Accessed Jul 2010.

15. HealthFinder.gov. U.S. Department of Health and Human Services. Office of Diseaese Prevention and Health Promotion. (ODPHP). http:// healthfinder.gov/. Accessed Jan 2010.

16. 2007 Behavioral Risk Factor Surveillance System Questionnaire. National Center for Chronic Disease Prevention and Health Promotion, Centers for Disease Control and Prevention. http://www.cdc.gov/brfss/ questionnaires/english.htm. Accessed Dec 2006.

17. National Center for Health Statistics, CEnters for Disease Control and Prevention. National Health Interveiw Survey: Questionnaires, Datasets, and Related Documentation 1997 to the Present. http:// www.cdc.gov/nchs/nhis/quest_data_related_1997_forward.htm. Accessed Dec 2006.

18. Dillman DA. Mail and Internet Surveys: The Tailored Design Method. 2nd ed. Hoboken NJ: John Wiley Company; 1999.

19. Edwards $P$, Roberts I, Clarke $M$, et al. Increasing response rates to postal questionnaires: systematic review. BMJ. 2002;324(7347):1183.

20. Maciosek MV, Coffield AB, Edwards NM, Flottemesch TJ, Goodman MJ, Solberg LI. Priorities among effective clinical preventive services: results of a systematic review and analysis. Am J Prev Med. 2006;31(1):52-61.
21. Ockene JK, Edgerton EA, Teutsch SM, et al. Integrating evidencebased clinical and community strategies to improve health. Am J Prev Med. 2007;32(3):244-252.

22. Krist AH, Woolf $\mathrm{SH}$, Frazier $\mathrm{CO}$, et al. An electronic linkage system for health behavior counseling effect on delivery of the $5 A^{\prime}$ s. Am J Prev Med. 2008;35(5)(Suppl):S350-S358.

23. Arroyave AM, Penaranda EK, Lewis CL. Organizational change: a way to increase colon, breast and cervical cancer screening in primary care practices. J Community Health. 2011;36(2):281-288.

24. Skinner CS, Campbell MK, Rimer BK, Curry S, Prochaska JO. How effective is tailored print communication? Ann Behav Med. 1999; 21(4):290-298.

25. Solberg LI, Brekke ML, Fazio CJ, et al. Lessons from experienced guideline implementers: attend to many factors and use multiple strategies. Jt Comm J Qual Improv. 2000;26(4):171-188.

26. Solberg LI, Davidson G, Alesci NL, Boyle RG, Magnan S. Physician smoking-cessation actions: are they dependent on insurance coverage or on patients? Am J Prev Med. 2002;23(3):160-165.

27. Crabtree BF, Nutting PA, Miller WL, Stange KC, Stewart EE, Jaen CR. Summary of the National Demonstration Project and recommendations for the patient-centered medical home. Ann Fam Med. 2010;8(Suppl 1):S80-90; S92.

28. National Prevention, Health Promotion, and Public Health Council. The National Prevention Strategy. http://www.healthcare.gov/center/ councils/nphpphc/index.html. Accessed Jul 2011.

29. U.S. Department of Health and Human Services. National Strategy for Quality Improvement in Health Care. FY 2010-2015. http://www. hhs.gov/secretary/about/priorities.html. Accessed Aug 2011.

30. Whitlock EP, Orleans CT, Pender N, Allan J. Evaluating primary care behavioral counseling interventions: an evidence-based approach. Am J Prev Med. 2002;22(4):267-284.

31. Whitlock EP, O'Connor EA, Williams SB, Beil TL, Lutz KW. Effectiveness of weight management interventions in children: a targeted systematic review for the USPSTF. Pediatrics. 2010;125(2):e396-e418.

32. Wilson DB, Johnson RE, Jones RM, Krist AH, Woolf SH, Flores SK. Patient weight counseling choices and outcomes following a primary care and community collaborative intervention. Patient Educ Couns. Jun;79(3):338-343.

33. Ralston JD, Coleman K, Reid RJ, Handley MR, Larson EB. Patient experience should be part of meaningful-use criteria. Health Aff (Millwood). 2010;29(4):607-613.

34. Silvestre AL, Sue VM, Allen JY. If you build it, will they come? The Kaiser Permanente model of online health care. Health Aff (Millwood). 2009;28(2):334-344.

35. The Patient Protection and Affordable Care Act. Section 4103. Public Law 111-148. 2nd Session ed; 2010.

36. Blumenthal D, Tavenner $M$. The "meaningful use" regulation for electronic health records. N Engl J Med. 2010;363(6):501-504.

37. American Academy of Family Physicians, American Academy of Pediatricians, American Osteopathic Association. Joint Principles of the Patient-Centered Medical Home. http://www.pcpcc.net/. Accessed May 2011.

38. The Office of the National Coordinator for Health Information Technology. U.S. Department of Health \& Human Services. Health IT. http://healthit.hhs.gov. Accessed Jul 2011. 